\title{
PREFACE
}

\section{Evolution of Firms and Industries}

\section{Takahiro Fujıмото}

Faculty of Economics, The University of Tokyo; 7-3-1 Hongo, Bunkyo-ku, Tokyo 113-0033, Japan.

*E-mail: fujimoto@e.u-tokyo.ac.jp

\section{Economies, Industries, Firms and Sites}

This special issue deals with the evolution of industries and firms. Both theoretical and empirical aspects are explored.

An industry is a collection of value-adding sites (e.g., factories, product development projects, service facilities) that share similar product-process design information. A firm is a collection of sites and headquarters that are controlled by a single capital. As such, firms today can be multi-national and multi-industrial, but local industries, by definition, stay within a country's border. Thus, the world economy is composed of global firms and local industries, whereas a national economy consists of local industries.

The most fundamental value-adding units of the economy are the sites, or "genba" in Japanese. The economy, industries, firms, and sites all evolve over time. Starting from the above-mentioned field observation, we try to integrate the dynamic analyses of firms and industries by focusing on the common component of the two-the manufacturing sites, including factories and development projects.

\section{Design Information and Its Evolution}

One of the key concepts for our industry-firm-site analysis is "design" (Fujimoto, 2007). Design means information or coordination that interconnects an artifact's functional and structural elements. A product (goods or service) is a tradable artifact which consists of design information and its medium, following Aristotle's logic of form and material. Production is nothing but the transmission of a product's design information to its media. Thus, design precedes production for a given product.

If the medium is tangible, the product in question is a hardware good that belongs to a manufacturing industry. If the medium is intangible or ephemeral, it is service (if its design information is functional) or software (if it is structural). In any case, design information is the major source of economic value-added.

Design information of an artifact, like genetic information of a living thing, evolves over time through variation-selection-retention, which is made by mar- 
kets, societies, firms and engineers. Innovation, in the Schumpeterian sense (Schumpeter, 1912/1934), is essentially the evolution of a new design, or a new combination of functions and structures of an artifact (e.g., product, process, etc.) that contributes to economic value-added.

\section{Capability-Building and Productivity Increase}

For now, we focus on manufacturing industries of trade goods, although the same logic can be applied to the service sectors in most cases. A manufacturing site (genba), in this context, is a place where value-carrying design information flows to the market. The flow is governed by technologies and routines. A system of routines that effectively govern the flow is called "organizational capability" in manufacturing (Nelson and Winter, 1982). Firms select core technologies, while their manufacturing sites accumulate capabilities, which in turn affect productivity of the sites.

Physical productivity (the inverse of the labor input coefficient) of a manufacturing site means efficiency of the design information flow to the market (Fujimoto, 1999). It follows that productivities of different factories or development projects may differ depending upon the firm's technological choices and/or the sites' capability-building (Womack et al., 1990; Clark and Fujimoto, 1991). Our analysis starts from the recognition of such inter-firm and international differences in productivities within a global industry.

We should note that the above view of industries can be seen as a dynamic interpretation of the Ricardian comparative advantage. Manufacturing routines and capabilities (e.g., the Ford System and the Toyota System), through their evolution process, create international productivity differences between factories and projects of the same industry (Fujimoto, 1999). Indeed, we often find productivity of a factory in country A to be three times or more as high as that of its competing factory in country B which adopted similar production technologies.

\section{A Dynamic Interpretation of Ricardian Comparative Advantages}

Starting from the international productivity differences that Ricardo assumed some 200 years ago (Ricardo, 1817), we may illustrate the evolution of the economies, industries, firms and sites as an interrelated process, as opposed to a separate one. We note that the Ricardian trade theory is generalized in such a way that it includes not only traded intermediate goods as inputs but it also can treat choice of techniques (Shiozawa, 2007). Thus the Ricardian trade theory is now well based on the assumption that commodities are produced by means of commodities (Sraffa, 1960).

First, evolution of a manufacturing site's capabilities causes productivity growths and differences, which influences country A's average productivity in industry X through market selection of high-productivity sites inside the country.

Second, different industries of Country A, with different patterns of capability- 
building processes and design architectures, show different levels of relative productivities vis-à-vis those in competing counties B, C, etc.

Third, the resulting profile of relative productivity ratios of industries $\mathrm{X}, \mathrm{Y}, \mathrm{Z}$, etc. between competing countries $\mathrm{A}$ and $\mathrm{B}$ affects relative wage ratios between the two countries (Fujimoto and Shiozawa 2011-12). In other words, the profile of all industries' relative productivity ratios vis-à-vis competing countries determines the relative wage ratio.

Fourth, as a result of the relative productivities and wages mentioned above, relative costs and prices of industries $\mathrm{X}, \mathrm{Y}, \mathrm{Z}$, etc., between the competing countries are revealed. In the long run, following the logic of Ricardian comparative advantage, the industrial portfolios of countries A, B, etc., emerge through the world market's selection of "comparatively advantageous industries" that demonstrate higher relative productivity ratios vis-à-vis their rival countries than other domestic industries.

However, the industrial structures of the trading countries may constantly change to the extent that capability-building competition between the sites and firms continues, and the products' design attributes (e.g., architecture) change. For instance, while the relative wage ratio between the two countries may change as their all-industry profiles of relative productivity ratios mentioned above change, further changes in relative productivity ratios may, in turn, change the patterns of the comparative advantage. If relative productivity ratios of industry $\mathrm{X}$ in countries $\mathrm{A}$ and $\mathrm{B}$ converge faster than relative wage ratios between the same two countries due to technological standardization, the lower wage country B may newly gain the comparative advantage vis-à-vis country A and thereby shift from importer to exporter status in industry $\mathrm{X}$, as Akamatu's "flying geese" theory suggested (Akamatsu, 1961, 1962; Kojima, 2000).

Fifth, manufacturing firms worldwide, in order to secure their profit and growth, will try to select certain advantageous combinations of products and locations by moving and expanding across countries and industries. Multi-national firms may find overseas locations of their manufacturing sites by balancing two principles - physical proximity to markets and comparative advantage. In this way, a firm's business structures will evolve through the selection of advantageous industries, products, architectures, technologies, site locations, and so on.

It is important to note that the above story follows the Ricardian logic of classical economics that the system of normal (natural) prices is determined by unit labor cost, or the combinations of labor productivities (labor input coefficients) and hourly wages. Besides, the present evolutionary analysis of firms and industries basically follows the assumption of classical economics (or its prominent successors as evinced by Sraffa) that prices and volumes of a given product are determined separately (Sraffa, 1926, 1960; Shiozawa, 1989, 2004), as opposed to the neo-classical (general equilibrium) assumption of simultaneous price-volume determination. 


\section{Why Do We Adopt Ricardian-Classical Logic?}

The choice of classical economics as the basis of the evolutionary analysis of industry performances is empirical rather than theoretical. Empirically at least, the prevalent practices that we observe in today's manufacturing industries simply fit the classical models better.

In the Japanese auto industry, for example, the manufacturing firm may set the price/cost target of a new product prior to its production by applying the "target costing" method, which explores a realistic combination of its design information, price, profit margin, unit cost and life-time sales volume by rationalizing its design (i.e., value engineering). We note here that, at this developmental (preproduction) stage, the relationship between the target cost and cumulative volume follows the logic of increasing return (i.e., long-term economy of scale) because each project incurs a fixed cost for product development.

Once its production starts, however, the product's normal prices are basically fixed, similar to the assumption of the "cost-plus" principle. Then manufacturing firms try to make accurate forecasts for the next months' sales, to make master production schedules accordingly, and to maximize their efforts to sell all the products that were actually produced (Sraffa, 1926; Shiozawa, 2004). When finished goods inventories are piling up or slow to move, price discounts may be conducted, which generates a gap between normal prices and market prices, but the former is still relatively stable. Quite simply, these practices in the real world, which include firms and factories and development projects, are closer to what classical economics has assumed for a long time.

Also, classical trade theories (Ricardian in particular) can, in many cases, better explain the reality of the world economy, such as the large international differences in both productivities and wages between advanced and emerging countries (Shiozawa, 2007). In the beginning of the 21 st century, for instance, average wages in China's major exporting factories in the machinery industries were less than $1 / 20$ of those in Japan, while the Japanese factories' productivities were in many cases 3 or more times higher than the Chinese counterparts (Fujimoto and Shiozawa, 2011-12). The standard models of neoclassical trade theories, which assume internationally identical production functions, are rather remote from the above reality on the shop floor.

More generally, the concepts of "industry", "industrial performance" and "industrial structure" have long been neglected or deemphasized in mainstream neoclassical theories. Industrial organization analysis is virtually applied micro economics, and inter-industry relationship analysis by input-output tables supplements macro economics, but economic analyses of the industrial structures and performances have not been actively done in today's mainstream economics, with some exceptions of trade theories and industrial agglomeration studies.

Marshall might have been the last mainstream economist who made significant efforts to analyze industrial dynamics (Marshall, 1890, 1919), but his followers, 
purifying the logic of general equilibrium theory, tended to stay away from this complex and messy phenomenon called "industry." Instead, industry, in relation to the neoclassical analysis of subjective equilibrium, was described often merely as an enlarged copy of the "representative firm."

Classical economics, by contrast, tended to emphasize the concept of industry in the context of theories of value, industrial structure, trade, distribution, industrial agglomeration, economic development, and so on. As we get into the 21st century, in which free trade and intra-industrial trade become more prevalent, we may need to pay more attention to a certain reality of classical economics regarding the evolutionary analyses of industries.

\section{Narrowing the Demand-Supply Gap}

If a product's price and volume are determined separately, the firms and sites may have to fill the demand-supply gap by their own efforts, because price mechanisms do not automatically fill the gap (Sraffa, 1926; Shiozawa, 2004). This is particularly the case when firms and sites are making constant efforts to increase productivities. Gap filling efforts are observed at the levels of sites, firms, industries and national economy. For now, we focus on the case of demand shortage or excess supply, or what Kornai described as "pressure" (Kornai, 1980).

In this context, a manufacturing site (a factory) is a local entity at which the local community expects stable employment. As such, the site makes continuous efforts for its own survival to increase productivity, lower costs and prices, and thereby persuade the headquarters and managers to choose this site despite the wage gap, appreciation of yen and other handicaps.

But this means that, given the production volume, the number of employees required by the factories decreases. That is, unless the demand grows fast enough to make up for the impact of the productivity increase, the firms may have to cut employment. This is the dilemma of productivity and employment.

At the firm level, there is a tension between its production unit (cost center) that generates opportunity loss (underutilized productive resources) by raising productivities on the one hand, and its headquarters or business unit (profit center) that try to compensate for this loss by strengthening their efforts for sales, product development, and business development on the other hand.

At the level of individual industries, the demand-supply gaps are regularly caused by changes in the country's overall industrial structure. When a large industry loses its comparative advantage due to rapid changes of competitive conditions, the demand-supply gap of this particular industry may force the firms there to reduce the large number of its employees or exit from the industry itself, which may generate frictional and structural unemployment-industrial "hollowing out." Many of Japan's digital electronics products have lost their competitive advantages since the 1990s, when their architectures quickly became modular (i.e., coordination-saving); a case in point is flat panel TV manufacturing. 
In this special issue, Fujimoto (2012) proposed a framework of "design-based comparative advantage," which may better explain the stylized fact that industries in post-World War II Japan tended to have an international competitive advantage in products with integral architectures or, coordination-intensive goods. This is, in a sense, an attempt to apply the logic of the Ricardian comparative advantage to not only comparative production cost but also comparative design cost.

Using this framework, Fujimoto's article argues that post-war Japan, where many manufacturing sites with a rich endowment of coordinative capability emerged for historical reasons (e.g., economy of scarcity), tended to enjoy designbased comparative advantages in integral (i.e., coordination-intensive) products rather than modular (coordination-saving) ones. This logic may persuasively explain why Japan's auto industry (relatively integral) sustains its competitive advantage, while its digital consumer appliances (relatively modular) quickly lost their competitiveness as of the early $21^{\text {st }}$ century.

At the level of a national economy, the demand-supply gap means the difference between the country's actual GDP (total demand) and potential GDP (total supply). The potential GDP is estimated by existing production inputs and total factor productivities. Given the amount of existing production inputs (e.g., labor), the macro demand-supply gap will become wider when the total demand shrinks, or when productivity increases.

In other words, if productivity increases in the country's manufacturing sector, the potential GDP becomes larger, and the gap widens accordingly. Conversely, the unemployment ratio may increase, unless the effective demand expands. In reality, Japan's total number of employees in its manufacturing sector decreased to become less than 10 million in 2012, partly because of stagnant demand and partly because of productivity increase.

\section{Creating Effective Demand at All Levels}

In the aforementioned situation where normal prices are determined separately from actual sales volume, persistent demand-supply gaps can occur at any level (sites, firms, industries and economies), so the gap-reducing efforts are made at all levels as well. When the supply excesses demand, these efforts consist of production volume reduction and demand volume generation.

At the level of manufacturing firms and sites, production schedules and operations are made according to demand forecasts or customer orders. When production capacity (potential supply) is excessive, a firm following mass production routines may produce at the full capacity, increase finished goods inventories, and then try to reduce them by strengthening sales efforts or reducing market prices. Another firm following Just-in-Time routines may reduce the production schedule to the level of predicted sales volume for selling the products at normal prices. Still others may intentionally set the production schedule lower than the predicted demand, accept opportunity cost of lost sales, produce at full capacity, and sell out 
the product at the normal price. In any case, the producers' efforts to sell as many as possible of the produced products at normal prices is common in all of the above three types.

When the demand-supply gap still remains, the firm may improve product designs, expand product varieties, introduce all new products, or lower normal prices by increasing productivity in order to improve the utilization ratios of its productive resources. Drucker (1973) emphasized creating customers by creating goods and services that can convert customers' potential needs to effective demand. Schumpeter argued that innovations that go beyond existing customers' imaginations are the engine of the economic growth (Schumpeter, 1912/1934). Ohno (1978) of Toyota suggested that continuous improvements of manufacturing flows and productivities at manufacturing sites can bring about constant reductions of normal prices of given products.

In any case, as Penrose (1959) pointed out, a firm's productive resources are essentially underutilized, which means that the firm's demand-creating efforts will continue endlessly.

If the demand-supply gap persists after the firms' demand creation efforts, the firms may give up their demand-expanding measures and turn to such supply-reducing measures as reducing employment, selling production equipment, closing down factories, and so on. At the industry level, these measures collectively mean transfers of productive resources between industries. Such resource transfer may occur within or between firms. If these transfers are large enough to create industrial hollowing out, governments may intervene and try to smooth such resource movements by certain industry-adjustment policies. If the gap still remains after such adjustment, what is left may be Keynesian public investment for creating effective demands at the macro-economic level.

In any case, the efforts of reducing the demand-supply gap includes reducing production schedules and/or productive resources, strengthening sales efforts, improving or innovating product designs, expanding product varieties, reducing normal prices by productivity increases, improving manufacturing qualities and delivery times, enhancing customers' ability and willingness to pay, and so on. Cutting market prices is certainly one such measure, but only one.

\section{Productivity and Variety}

In the above-mentioned way, manufacturing sites tend to strengthen their efforts to increase their productivities for their own survival, particularly when total demand is insufficient and inter-firm and inter-site competitions are getting tougher. If such productivity increases consequently widen the demand-supply gaps and the firms' productive resources become less utilized, the firms may introduce new products and expand product varieties in order to fill the gap. Thus, evolutions of firms, industries and sites under the situation of insufficient demand ("pressure economy" in Kornai's (1980) term) may bring about productivity increase and va- 
riety expansion at the same time.

In this special issue, Shiozawa (2012) focused on the impact of a firm's product variety expansion as its effort to capture additional effective demand, and he clarified certain logic for calculating optimal product variety in the case of a monopolist firm. That is, Shiozawa assumed that the firm can estimate the maximum sales that it can capture by introducing an infinite number of new products, or the "potential sales volume," and he defined a fraction of the potential sales volume that the company can capture by N products as "estimated coverage function."

It follows that the firm may keep on introducing additional new products as long as the additional profit of the next new product estimated by its coverage function exceeds its fixed development cost. In this way, Shiozawa (2013) emphasized product variety expansion as a firm's major tool by which it can capture additional effective demand.

Here exists another dilemma, though. When a firm makes significant efforts to improve productivity significantly within a certain industry (e.g., introduction of the Ford production system), the technology and equipment that contribute to high productivity tend also to be product-specific (e.g., special purpose machines and tools), which may hamper subsequent product renewals (innovations) and variety expansions for demand generation. Abernathy (1978) called this "productivity dilemma", based on his long-range analysis of the evolution of the US auto industry.

There are certain ways to alleviate this dilemma, including flexible production technologies (e.g., numerical control machines) and production systems (e.g., the Toyota System), product modularization, and so on. History tells us that it is rather difficult to avoid this dilemma completely.

In this special issue, Ikuine (2012) indicates that similar kinds of dilemmas exist in not only hardware manufacturing industries (e.g., automobiles) where productspecificity of high-productivity processes matters, but also intangible goods industries such as game software. That is, the patterns of technological evolutions within a particular industry which Abernathy characterized in the automobile industry, or the shift from radical to incremental innovations, are observed in the video game industry as well.

Ikuine suggests that accumulation of knowledge, which is used repeatedly in a series of game software development projects, makes the incremental product development more economical and risk-avoiding than radically new ones, which results in the dominance of the former at the later stage of its industry lifecycle. He calls this phenomenon the "development productivity dilemma." Thus, the demand-creating power of new products gradually decreases in not only traditional manufacturing sectors but also knowledge-based sectors. There are insufficient varieties of radically innovative goods in this case.

Another problem is that the competing firms' efforts for variety expansion often result in excessive variety, which means that the additional product variety does 
not create enough demand to justify its fixed development cost. Shiozawa's aforementioned article (2012) also points out that the firms under oligopolistic competition tend to introduce excessive number of new products, whereas monopolist firms are more likely to reach the optimal product variety.

\section{Conclusion}

With the above mentioned thoughts and predictions, this special issue presents some of our efforts for analyzing the evolution of firms and industries in an integrated way. The authors of all the articles are members of the JAFEE study group on evolutions of firms and industries, which has held regular bimonthly meetings in Tokyo in the past years, presenting and discussing various issues regarding this topic. The articles in this special issue are only a small part of the outcome of this group.

Most of our research studies are still at the exploratory stage, so further theoretical and empirical studies are necessary. At the same time, many of the concepts and the logic presented in this issue are not particularly new. We have been significantly influenced by Ricardian and other classical economics, Sraffa and other successors of classical economics, Marshall's industrial economics, Schumpeter's innovation theory, empirical insights of the Oxford Economists' Research Group study, the ideas of effective demand generation or customer creation by Keynes and Drucker, practical studies of the Toyota system and its flow management, firms, routine-capability-based theories of firm-industry-economic evolution, dynamic analysis of product-process innovations, design theories including the concept of architectures, and so on.

One thing which might be somewhat new is our emphasis on the reality and logic of the manufacturing sites (genba) as the basic research unit of our evolutionary analysis. Certainly, the continuous and tenacious efforts of factories and development projects to build manufacturing capabilities and product-process deigns are the engine of evolution of firms and industries. The recognition and observation of micro-macro loops between sites, firms, industries and economies are the starting point of our "genba-based" theories of evolution.

\section{References}

Abernathy, W. J. (1978) The Productivity Dilemma, Johns Hopkins Press, Baltimore.

Akamatsu, K. (1961) "A Theory of Unbalanced Growth in the World Economy," Weltwirtschaftliches Archiv 86: 196-217.

Akamatsu, K. (1962) "A historical pattern of economic growth in developing countries," The Developing Economies 1 (Supplement s1): 3-25.

Clark, K. B. and T. Fujimoto (1991) Product Development Performance, Harvard Business School Press, Boston.

Drucker, P. F. (1973) Management: Tasks, Responsibilities, Practices, Harper \& Row, New York. 
Fujimoto, T. (1999) The Evolution of a Manufacturing System at Toyota, Oxford University Press, Oxford.

Fujimoto, T. (2007) "Architecture-based comparative advantage: A design information view of manufacturing," Evolutionary and Institutional Economics Review 4: 55-112.

Fujimoto, T. (2012) "An economic analysis of architecture and coordination: Applying Ricardian comparative advantage to design costs and locations," Evolutionary and Institutional Economics Review 9.1: 51-124.

Fujimoto, T. and Y. Shiozawa (2011-12) "Inter and intra company competition in the age of global competition: A micro and macro interpretation of Ricardian trade theory," Evolutionary and Institutional Economics Review 8.1-2: 193-231.

Ikuine, F. (2012) "A study on the factors of the industry evolution-An empirical research of home video game software industry in Japan-," Evolutionary and Institutional Economics Review 9.1: 37-50.

Kojima, K. (2000) ““The Flying Geese” Model of Asian Economic Development: Origin, Theoretical Extensions, and Regional Policy Implications," Journal of Asian Economics 11: 375-401.

Kornai, J. (1980) Economics of Shortage (2 vols.), North Holland, Amsterdam.

Lee, F. (1981) "The Oxford Challenge to Marshallian Supply and Demand: the History of the Oxford Economists' Research Group," Oxford Economic Papers, New Series 33.3: 339-351.

Marshall, A. (1890) Principles of Economics, Macmillan, London.

Marshall, A. (1919) Industry and Trade, Macmillan, London.

Nelson, R. R. and S. G. Winter (1982) An Evolutionary Theory of Economic Change, Harvard University Press, Cambridge, MA.

Ohno, T. (1978) Toyota Production System (in Japanese), Daiyamondo-sha, Tokyo.

Penrose, E. T. (1959) The Theory of the Growth of the Firm, Basil Blackwell, Oxford.

Ricardo, D. (1817) On the Principles of Political Economy, and Taxation, John Murray, London.

Schumpeter, J. A. (1912/1934) The Theory of Economic Development, Harvard University Press, Cambridge, MA.

Shiozawa, Y. (1989) "The Primacy of Stationarity: A Case against General Equilibrium Theory," Osaka City University Economics Review 24.1: 85-110.

Shiozawa, Y. (2004) "Evolutionary Economics in the 21st Century: A Manifest," Evolutionary and Institutional Economics Review 1.1: 4-47.

Shiozawa, Y. (2007) "A New Construction of Ricardian Trade Theory / A Many-country, Many-commodity Case with Intermediates Goods and Choice of Production Techniques," Evolutionary and Institutional Economics Review 3.2: 141-187.

Shiozawa, Y. (2012) "Estimating Optimal Product Variety of Firms," Evolutionary and Institutional Economics Review 9.1: 11-35.

Sraffa, P. (1926) “The laws of returns under competitive conditions," The Economic Journal 36.144: 535-550.

Sraffa, P. (1960) Production of Commodities by Means of Commodities: Prelude to a Critique of Economic Theory, Cambridge University Press, Cambridge, UK.

Womack, J., D. T. Jones and D. Roos (1990) The Machine that Changed the World, Rawson Associates, New York. 